Parent-Child Similarity in Common and Specific Components of Prejudice:

The Role of Ideological Attitudes and Political Discussion

Cecil Meeusen ${ }^{1} \&$ Kristof Dhont ${ }^{2,3}$

${ }^{1}$ Centre for Sociological Research, University of Leuven, Belgium

${ }^{2}$ School of Psychology, University of Kent, UK

${ }^{3}$ Department of Developmental, Personality and Social Psychology, Ghent University,

Belgium

Meeusen, C. \& Dhont, K. (2015). Parent-child similarity in common and specific components of prejudice: The role of ideological attitudes and political discussion. European Journal of Personality, 29, 585-598.

http://onlinelibrary.wiley.com/wol1/doi/10.1002/per.2011/abstract 


\begin{abstract}
Using a representative sample of Belgian adolescents $(N=1,530)$ and both their parents, we investigated the parent-child similarity in prejudice toward different outgroups and ideological attitudes (right-wing authoritarianism and social dominance orientation). Contrary to previous studies, we distinguished between common and specific components of prejudice to test whether the parent-child similarity in one specific type of prejudice was symptomatic of parent-child similarity in prejudice toward outgroups in general. Second, we evaluated whether the parent-child similarity in common and specific components of prejudice was related to the parent-child similarity in ideological attitudes. Third, we investigated the moderating role of political discussion in the intergenerational framework of ideology and prejudice. Results indicated that parent-child similarity was particularly pronounced for the common rather than the specific component of prejudice and that the similarity in ideological attitudes was partly related to the similarity in the common component of prejudice. Finally, adolescents who discuss social and political issues more ( $v s$ less) frequently with their parents, more strongly resembled their parents in the common component of prejudice and levels of authoritarianism. These results suggest that generalized prejudice runs in families and highlight politicization of the family as an important socialization mechanism.
\end{abstract}

Keywords: Intergenerational similarity, prejudice, authoritarianism, social dominance, political discussion 


\section{Parent-Child Similarity in Common and Specific Components of Prejudice: The Role of Ideological Attitudes and Political Discussion}

The personality-oriented approach to prejudice originates from the classic notion and empirical finding that different forms of prejudice, targeting different outgroups (e.g. homosexuals, immigrants, Muslims), are typically correlated (Adorno, Frenkel-Brunswik, Levinson, \& Sanford 1950; Allport, 1954). Scholars have considered this "generality of prejudice" as a strong indication that individual differences in prejudice vary as a function of stable personality attributes (e.g., Altemeyer, 1981; Ekehammar \& Akrami, 2003; Pratto, Sidanius, Stallworth, \& Malle, 1994; for a review, see Hodson \& Dhont, 2015). Personality research to date has identified several individual difference variables such as personality traits (Sibley \& Duckitt, 2008) and cognitive factors (Dhont \& Hodson, 2014a; Roets \& Van Hiel, 2011), predicting prejudice, but due to the focus on individual-level variables, familial influences (i.e. genetic or socialization influences) have often been ignored in attempts to understand the structure of generalized and specific types of prejudice. Early theorizing nevertheless highlighted the role of the family context, particularly parental influence, in the development of prejudice in children (Allport, 1954) and only recently, studies have shown the significant heritability of generalized prejudice (Lewis, Kandler, \& Riemann, 2014; Orey \& Park, 2012). Highly relevant in this discussion is Degner and Dalege's (2013) recent suggestion based on their meta-analytic findings regarding the parent-child similarity in intergroup attitudes. These authors proposed that the similarity between parents and children might be most pronounced for broad ideological attitudes and general attitudes toward all types of outgroups, rather than for specific attitudes towards particular outgroups. Yet, a systematic investigation explicitly testing this assumption is currently lacking. 
In this article, we integrated person-based and developmental approaches to prejudice by investigating parent-child similarity in prejudice toward multiple outgroups as well as parent-child similarity in ideological attitudes (i.e., right-wing authoritarianism and social dominance orientation). Furthermore, we investigated if discussion about social-political issues at home moderated these relations, thereby testing an important socialization mechanism that might facilitate intergenerational similarity.

\section{Individual Differences Approach to Prejudice}

Initiated by the seminal works of Allport (1954) and Adorno et al. (1950), considerable research has demonstrated that prejudices toward a variety of outgroups are significantly interrelated (e.g., Ekehammar, Akrami, Gylje, \& Zakrisson, 2004; Kteily, Ho, \& Sidanius, 2012; Zick et al., 2008). Relying on cross-sectional and longitudinal data from German probability surveys, Zick et al. (2008) for instance, found a strong general factor underlying eight different types of prejudice (e.g., sexism, racism, Islamophobia, and homophobia), which was highly stable across time. These studies provided support for Allport's (1954) notion that "people who reject one out-group will tend to reject other out-groups. If a person is anti-Jewish, he is likely to be anti-Catholic, anti-Negro, anti any out-group" (1954, p. 68). Hence, previous research suggests that a substantial amount of variance in prejudice can be explained independent of target outgroup, indicating that different types of prejudice share a common component representing a generalized tendency to be prejudiced toward any outgroup (Akrami, Ekehammar, \& Bergh, 2011; Ekehammar \& Akrami, 2003; Zick et al., 2008).

Numerous studies have indicated that different types of prejudice are predicted by common individual-difference factors. More specifically, scholars identified two primary and complementary individual-difference variables, right-wing authoritarianism (RWA, Altemeyer, 1981) and social dominance orientation (SDO, Pratto et al., 1994), predicting 
outgroup prejudice and justification of exploitation of outgroup members across multiple domains, including racial and ethnic prejudice, sexism, and speciesism (e.g., Altemeyer, 1996; Dhont \& Hodson, 2014b; Duckitt, Wagner, du Plessis, \& Birum, 2002; Roets, Van Hiel, \& Dhont, 2012; Zick et al., 2008). RWA reflects a covariation of adherence to traditionalism, uncritical submission to authorities, and aggressiveness towards norm violators (Altemeyer, 1981). SDO is defined as a generalized desire for group-based dominance and inequality among social groups in society (Pratto et al., 1994, Sidanius \& Pratto, 1999). Originally, RWA and SDO have been introduced as fixed personality characteristics, but more recent theorizing (e.g., Duckitt, 2001; Van Hiel, Pandelaere, \& Duriez, 2004) has considered these concepts as ideological attitude dimensions driven by core personality traits (Ekehammar et al., 2004; Hodson, Hogg, \& MacInnis, 2009; Van Hiel, Cornelis, \& Roets, 2007; Sibley \& Duckitt, 2008).

\section{Parent-Child Similarity in Prejudice: Empirical Evidence}

At first sight, empirical studies on the parent-child similarity in prejudice seem to have produced mixed support for the theoretically proposed intergenerational similarity of prejudice. Some studies reported weak or no parent-child similarity (e.g., Aboud \& Doyle, 1996; Branch \& Newcombe, 1986) while other studies obtained convincing evidence for such similarity (e.g., Dhont, Roets, \& Van Hiel, 2013; Duriez \& Soenens, 2009; Meeusen, 2014a; Rodríguez-García \& Wagner, 2009). Assembling data from 131 studies (total $N>45,000$ parent-child dyads), a recent meta-analysis (Degner \& Dalege, 2013) clearly confirmed the positive relations between the prejudice levels of parents and children, revealing a mean effect size of $r=.29$, and up to $r$ $=.38$ when controlling for low reliability in measures. The parent-child similarity was found to be comparable across affective, cognitive, and behavioral components of prejudice and neither gender nor parent-child gender match moderated this relation. Although part of this association might be explained by possible influences that children have on their parents, 
studies testing non-recursive structural equation models (Rodríguez-García \& Wagner, 2009) or adopting a longitudinal design (Vollebergh, Iedema, \& Raaijmakers, 2001) reported that the transmission effect of parents on children is significantly stronger than the reverse effect.

A particularly noteworthy finding of Degner and Dalege's (2013) meta-analysis was that parent-child similarity significantly varied across different domains of prejudice. More specifically, highest effect sizes were observed for national or immigration-related attitudes and generalized prejudice, as compared to more group-specific types of prejudice based on gender, race, or ethnicity (e.g. O’Bryan, Fishbein, \& Ritchey, 2004). According to Degner and Dalege (2013), these differences may indicate that especially intergroup attitudes reflecting an overall orientation toward outgroups in general are transmitted from parents to children. As such, the authors suggested that children are likely to adopt parents' generalized tendency to be prejudiced toward any outgroup (i.e., the component that different types of prejudice share in common) rather than being influenced by parents' attitudes toward specific groups (i.e., the variance unique to a specific type of prejudice). Precisely the common, rather than the specific, component in prejudice is more strongly rooted in broader right-wing ideological orientations such as RWA and SDO (Cunningham, Nezlek, \& Banaji, 2004; Dhont, Hodson, Costello, \& MacInnis, 2014; Ekehammar et al., 2004; Zick et al., 2008) and is likely transferred from parents to children through the transmission of these ideological attitudes. Indeed, additional to exhibiting similar levels of prejudice, research demonstrated that parents and children also resemble in their levels of RWA (e.g., Dhont et al., 2013; Duriez, Soenens, \& Vansteenkiste, 2008; Peterson \& Duncan, 1999) and SDO (Chatard \& Selimbegovic, 2008; Duriez et al., 2008).

Building upon previous insights that a) RWA and SDO are strong predictors of prejudice and b) there is significant parent-child similarity in RWA, SDO, and prejudice, Duriez and Soenens (2009) proposed that prejudice is partly transferred through direct modelling processes 
and partly transferred through right-wing ideological attitudes (see also Dhont \& Van Hiel, 2012). More specifically, Duriez and Soenens (2009) showed that parental RWA and SDO are both related to child prejudice via two pathways (see Figure 1). One pathway proceeds via child RWA (path A-E) (or child SDO, path D-G, respectively) and includes the parent-child similarity in RWA (or SDO). The other pathway (path B-F for RWA and path C-F for SDO) proceeds through parental prejudice and includes the parent-child similarity in prejudice. As such, the findings of Duriez and Soenens (2009) support an integrative mediation model of intergenerational similarity in ideology and prejudice. However, because previous studies (e.g., Dhont \& Van Hiel, 2012; Duriez \& Soenens, 2009; Meeusen, 2014a) typically investigated only one specific type of prejudice (e.g. ethnic prejudice), it remained unclear whether this model only applies to specific types of prejudice or whether previous findings are actually a reflection of parent-child similarity in generalized prejudice (cf. Degner \& Dalege, 2013). The present study addressed this gap in the literature by investigating parent-child similarity in common and specific components of different types of prejudice and the extent to which these components are related to parent-child similarity in ideological individual differences.

[Figure 1]

\section{Parent-Child Similarity in Prejudice: Familial Socialization and Genetic Influence}

From a developmental perspective, Allport (1954) distinguished two socialization processes through which parents transfer their attitudes to their offspring. On the one hand, children directly adopt parental prejudice by imitating and conforming to overt verbal and nonverbal parental expressions of prejudice. On the other hand, parents indirectly transmit negative intergroup attitudes through authoritarian parenting and by creating a strictly hierarchical

environment, leading to the development of a hierarchical view of social relations. Along similar lines, Adorno et al. (1950) suggested that strict discipline, harsh punishment, and being 
unresponsive result in authoritarian and prejudiced children. According to the socialization perspective, parents engage as socializing agents by acting as role models for their children and by communicating ideological values (Altemeyer, 1996; Duriez, Soenens, \& Vansteenkiste, 2007; Duriez et al., 2008). Such forms of social learning imply that parent-child similarity is dependent upon conditions that facilitate or obstruct the socialization process (see also Bandura, 1977).

Recent findings from behavioral genetic research seem to challenge this familial socialization interpretation of parent-child similarity. Relying on classic twin designs, researchers have estimated the heritability of prejudice and ideological attitudes by comparing the similarity correlations of monozygotic twins with those of dizygotic twins (e.g. Lewis \& Bates, 2010; Lewis et al., 2014; Ludeke, Johnson, \& Bouchard, 2013; McCourt, Bouchard, Lykken, Tellegen, \& Keyes, 1999; Orey \& Park, 2012). The results of these studies consistently indicated that almost all similarity between twins in their prejudice and ideological attitudes could be attributed to genetic heritability, whereas shared environmental effects such as familial socialization practices explained only a limited portion of the similarity between twins (McCourt et al., 1999; Olson, Vernon, Harris, \& Jang, 2001; Orey \& Park, 2012). In other words, these findings seem to contradict the traditional socialization perspective and suggest that parents exercise little influence on the attitude formation of their children (Eaves \& Hatemi, 2008). However, most of these studies were conducted among adult twin samples while the impact of shared environment and socialization processes can be expected to be more strongly pronounced in earlier stages in life, when parents have more control over their children. Indeed, several studies found that the impact of genetic and environmental factors on social, political, and religious attitudes varied across the life-span and showed that genetic influences were almost absent during adolescence, while familial socialization seemed of paramount importance for attitude development during that time (e.g., Eaves et al., 1997; Eaves, Hatemi, Prom- 
Womley, \& Murrelle, 2008; Hatemi et al., 2009). When adolescents leave their home environment and become more independent, the importance of genetic factors increased at the cost of the shared environment influences.

With regard to social and ideological attitudes, the degree of politicization of the family and the consistency and frequency of cues provided by family members has been considered an important facilitator of parent-child similarity (Jennings, Stoker, \& Bowers, 2009). Recent studies, for instance, showed that more frequent discussion about social and political issues at home related to stronger parent-child similarity in environmental concern and vote choice (Hooghe \& Boonen, 2015; Meeusen, 2014b). In line with these recent studies, we included political discussion as moderator of parent-child similarity in ideological attitudes and prejudice. Surprisingly, political discussion at home has not yet been investigated in relation to intergenerational similarity of ideology and prejudice, yet this may prove to be an important facilitator of parent-child similarity.

\section{The Present Research}

Previous studies on the intergenerational similarity of prejudice (Dhont \& Van Hiel, 2012; Duriez \& Soenens, 2009; Meeusen, 2014a) did not distinguish between common and specific components of prejudice as they investigated only one specific type of prejudice, e.g., ethnic prejudice. As such, to the best of our knowledge, no previous study has tested whether the observed parent-child similarity in one specific type of prejudice may actually be symptomatic of parent-child similarity in prejudice toward outgroups in general.

The first goal of the present study was to test this suggestion by investigating parentchild similarity in different types of prejudice (i.e., toward different target outgroups). Building on the work of Akrami and colleagues (2011), we distinguished between on the one hand, the common component of prejudice, consisting of the variance that a certain type of prejudice 
shares with other types of prejudice, and on the other hand, specific components of prejudice, tapping the variance that is unique to each type of prejudice. In line with the rationale outlined above and with Degner and Dalege's (2013) theoretical argument, we hypothesized that the parent-child similarity would be particularly pronounced for the common rather than the specific component of prejudice (Hypothesis 1).

Second, we included RWA and SDO in the model to evaluate whether parent-child similarity in common and specific types of prejudice is more deeply rooted in the parent-child similarity in ideological attitudes. Because RWA and SDO have been considered strong predictors of the common core of prejudice (Kteily et al., 2012; McFarland, 2010; Zick et al., 2008) and because significant parent-child similarity in SDO and RWA has been found in previous research (Dhont \& Van Hiel, 2012; Duriez \& Soenens, 2012), we expected that parentchild similarity in RWA and SDO would, at least partly, account for similarity in the common component of prejudice but not necessarily for the specific components of prejudice. In other words, in testing the mediation model of intergenerational similarity in ideology and prejudice (Figure 1), we hypothesized that parental ideology would be indirectly related to child prejudice through child ideology and parental prejudice when it comes to the common rather than the specific component of prejudice (Hypothesis 2).

Our third goal was to extend previous literature by investigating the moderating role of politicization of the family context in the intergenerational framework of ideology and prejudice. More specifically, we focused on discussion about social and political issues as an important indicator of politicization (Hooghe \& Boonen, 2015; Jennings et al, 2009; Meeusen, 2014b) and tested its facilitating role in the parent-child similarity in ideology and prejudice. We hypothesized that the parent-child similarity would be stronger when political and social issues are more regularly discussed (Hypothesis 3). Importantly, because previous research found family members to be influenced by the same social environment likely affecting 
attitudinal similarity between parents and children (Vollebergh et al., 2001), we controlled for the shared socio-economic environment to rule out this potential confound.

An important unique feature of the present study was the use of a large, representative sample of randomly selected adolescents to test our hypotheses. Indeed, the majority of prejudice research on intergenerational similarity (Degner \& Dalege, 2013) has relied on convenience and rather small samples, which limited the generalizability of previous findings. Furthermore, we assessed parental attitudes by directly surveying the parents instead of relying on children's reports of parental attitudes and by including both mothers and fathers in our study instead of only one parent. This way, we did not rely on indirect information that might bias the results and overestimate parent-child similarity (Degner \& Dalege, 2013).

\section{Method}

\section{Participants and procedure}

Data for this study were collected as part of one wave of the Parent-Child Socialization Study (PCSS 2012-2013; see Hooghe et al., 2013 for further details), a two-wave panel survey study among a representative sample of adolescents and both their parents in Flanders (the Dutch-speaking region of Belgium) and Brussels. Sixty-one secondary schools were randomly selected by means of a proportional stratified sample based on province and education track. We used the data of the second wave (collected in 2013) as only this wave included all required measures.

A team of researchers visited the schools and asked all students in the fourth year (i.e. US equivalent of $11^{\text {th }}$ grade) to complete a questionnaire about social and political issues during class hours $(N=3,598)$. Students who have switched schools since Wave 1 or repeated their third year received the questionnaire by mail ( $n=3,296$ in school, $n=302$ by mail). The students also received a similar questionnaire for their mother and father. Parents were asked to fill in 
the survey individually at home without discussing the content of the questionnaire with someone else. Questionnaires were returned in a pre-stamped, closed envelope to assure confidentiality of their answers. After two reminders (by telephone and/or by mail), questionnaires of $1,943(54.00 \%)$ of mother-father-child triads have been returned $\left(M_{\text {age-mother }}\right.$ $=45.51, \mathrm{SD}=4.22$, range 33-72; $M_{\text {age-father }}=47.77, \mathrm{SD}=4.87$, range 33-80; $M_{\text {age-child }}=16.37$, $\mathrm{SD}=.70$, range $14-19 ; 52.80 \%$ boys; $47.20 \%$ girls; $45.00 \%$ general education; $35.80 \%$ technical education; $3.10 \%$ artistic education; $16.10 \%$ vocational education).

For the purpose of the current study, only majority group members (i.e. both parents are born in Belgium) were included in the analyses. In total 407 triads were deleted from the sample because no information about the country of birth of the parents was available $(n=160)$ or because one of the parents had a migration background $(n=247)$, resulting in a sample of 1,536 native triads. ${ }^{1}$ Finally, six respondents who returned the questionnaire by mail did not indicate their current education track and could not be included in the final sample $(N=1,530)$.

\section{Measures}

Prejudice. Parents and children were asked to express their attitudes toward four different target groups: immigrants, Muslims, gays and lesbians, and women. Each type of prejudice was measured with multiple items rated on four-point Likert scales ranging from 'totally disagree' to 'totally agree'. Scores on each of the prejudice scales were computed by averaging the scale items and were coded so that higher scores indicated higher levels of prejudice.

Anti-immigrant prejudice was measured with eight items including 'the presence of immigrants increases criminality in our country' and 'if a country wants to reduce tension it should stop immigration' (Boonen, Meeusen \& Quintelier, 2014; Meeusen, 2014a). The scale 
proved to be one-dimensional and reliable for mothers $(\alpha=.89)$, fathers $(\alpha=.89)$, and children $(\alpha=.88)$.

Anti-Muslim prejudice was assessed with five items. Sample items were 'most Muslims in our country respect the culture and way of life of others' (reverse scored) and 'Muslims are dangerously fanatic' (partially based on Savelkoul, Scheepers, Tolsma, \& Hagendoorn, 2010). The scale was one-dimensional and reliabilities were satisfactory, $\alpha_{\mathrm{mother}}=.85, \alpha_{\mathrm{father}}=.85$, and $\alpha_{\text {child }}=.82$.

Anti-gay prejudice was measured with five items of the Homophobia scale developed by Wright, Adams, and Bernat (1999; see also Hooghe \& Meeusen, 2012). Sample items were 'it does not matter whether my friends are gay or straight' (reverse scored) and 'homosexuality is acceptable to me' (reverse scored). Scale reliability was good and the scale proved to be onedimensional; $\alpha_{\text {mother }}=.84, \alpha_{\mathrm{father}}=.85$, and $\alpha_{\text {child }}=.90$.

Finally, five items measured sexism, e.g., 'when jobs are scarce, men should have more right to a job than women' and 'a woman should be prepared to cut down on her paid job for the sake of her family' (Amato \& Booth, 1995; Hooghe \& Meeusen, 2012). The scale was onedimensional and the reliability proved to be good for mothers $(\alpha=.72)$, fathers $(\alpha=.75)$, and children $(\alpha=.70)$.

Ideological attitudes. Due to restrictions on survey length, RWA and SDO were each measured with three items adapted from Altemeyer (1981) and Pratto et al. (1994), respectively. A typical item for SDO was 'it is normal that some people get more of a chance in life than others'. A sample item of RWA was 'to maintain order in society, we have to crack down harder on people who do not follow the rules'. Both scales were one-dimensional and the reliability coefficients were $\alpha_{\text {child }}=.53 ; \alpha_{\text {mother }}=.58 ; \alpha_{\text {father }}=.57$ for SDO, and $\alpha_{\text {mother }}=.70, \alpha_{\text {father }}=.69$, and $\alpha_{\text {child }}=.60$, for RWA. ${ }^{2}$ 
Political Discussion. Children were asked to indicate on a four-point scale ranging from 'never' to 'often' how regularly they discuss four political and societal topics (general politics, European issues, environmental pollution, and issues related to other countries and cultures) with their mother and with their father. Factor analysis indicated that the discussion scale was one-dimensional and the internal consistency was good for both 'discussion with mother' $(\alpha=$ $.77)$ and 'discussion with father' $(\alpha=.78)$.

Control variables. Gender, education track of the child (general, technical, artistic, and vocational education track), education level of the parent (primary education, lower secondary education, higher secondary education, higher non-university, and university education), and political interest of the child ('how interested are you in societal problems and politics?' fourpoint scale ranging from 'not interested at all' to 'very interested') were included as control variables.

\section{Results}

\section{Descriptive Statistics and Correlations among Measures}

To retain the sample of 1,530 mother-father-child triads, missing values were imputed prior to analyses, using the expectation maximization algorithm available in SPSS. The proportion of missing values ranged between $0.26 \%$ and $4.69 \%$ for all items. Applying Maximum Likelihood procedures to deal with missing data has been shown to produce more reliable estimates as compared to conventional methods such as listwise deletion (Schafer \& Graham, 2002).

Table 1 presents descriptive statistics for all variables, the correlations between the prejudice measures (i.e., scale scores) as well as the associations of all prejudice measures with ideological attitudes and political discussion. As expected, correlational analyses indicated significant mother-child and father-child similarity in all types of prejudice, $r$ s ranging from .19 
to $.33, p s<.001$ (see Table 1, values in bold). Overall, the effect sizes were comparable to the mean effect size of .29 found in the meta-analysis of Degner and Dalege (2013). Furthermore, in line with the meta-analytic results, no significant differences were found between the effects sizes of mother-child similarity and father-child similarity ( $p s>.05)$. Importantly, all types of prejudice were positively correlated within each subsample, suggesting the existence of a common component of prejudice. ${ }^{3}$ Also, all prejudice types of mother and father were positively correlated.

All types of prejudice were also significantly correlated with SDO and RWA, with strongest associations for RWA with anti-immigrant and anti-Muslim prejudice. Furthermore, several prejudice types were negatively associated with political discussion at home (Table 1, bottom rows), indicating that the more often societal and political issues are discussed at home the lower the levels of prejudice. Finally, as can be seen in Table 2 (values in bold), parents and children also showed significant correspondence in their levels of RWA and SDO.

[Table $1 \&$ Table 2]

\section{Intergenerational Similarity in Common and Specific Components of Prejudice}

To distinguish between specific and common components of prejudice, we followed the statistical procedures of Akrami et al. (2011) using regression analyses. First, one type of prejudice (e.g. anti-immigrant prejudice) was entered as the dependent variable and regressed on the three other types of prejudice (e.g. anti-Muslim prejudice, anti-gay prejudice, and sexism). The residual of this regression analysis represented the specific component of prejudice, tapping the variance unique to a certain type of prejudice (Akrami et al., 2011). Second, to derive the common component - the shared variance with any other prejudice measure - the specific component was entered as predictor of the corresponding original 
prejudice score. The residual of this regression analysis represented the common prejudice component. This procedure was applied to all four prejudice measures.

The operationalization of the common component refers to any kind of overlap between one prejudice measure with any of the three other measures, consistent with Akrami et al. (2011). This operationalization is slightly different from how some other studies operationalized generalized prejudice, namely the variance simultaneously shared by all prejudice measures together (e.g. Ekehammar et al., 2004; Zick et al. 2008). However, we also computed a general prejudice factor using Principal Component Analysis with all four prejudice scales, capturing the variance shared by all four prejudices simultaneously, and conducted all analyses twice to check for consistency across operationalizations; once with the common prejudice component based on the regression residuals and once with the general prejudice factor from the PCA. Factor loadings on this general prejudice factor ranged from .63 to .84 for the children, from .31 to .89 for mothers, and from .53 to .87 for fathers.

Next, we investigated parent-child correspondence in specific and common components of prejudice, using the residual regression scores. In a series of regression analyses, we regressed each of the specific and common prejudice components of the children on the corresponding specific/common prejudice component of the mothers and fathers, while controlling for gender, education track, parental education level, discussion at home and political interest of the child. The results of these analyses are reported in Table 3A for mothers and 3B for fathers (standardized coefficients). These analyses revealed that parents and children showed significant correspondence in both the specific and common components of prejudice across all four prejudice types. Critically, however, parent-child similarity associations were consistently stronger for the common than for the specific components of prejudice, confirming Hypothesis 1 . In addition to the analyses using the common component scores (based on regression residuals), we conducted regression analyses using the generalized prejudice factors 
derived from the PCA. Similar to the findings of the common components, parents and children showed significant correspondence in this generalized prejudice factor (see last column of Table $3 \mathrm{~A}$ and $3 \mathrm{~B})$.

To test if the parent-child similarity would be stronger for gender matching dyads (i.e., mother-daughter and father-son) than for gender non-matching dyads (i.e., mother-son and father-dyads), we conducted moderation analyses including gender of the child as the moderator of the parent-child similarity. These analyses did not yield any significant difference in parentchild similarity between gender matching and non-matching dyads, all $p s>.10$ (see bottom rows of Table 3A and 3B), except for the mother-child similarity in the specific components of sexism and anti-immigrant prejudice which was stronger for girls than for boys $(p s<.05)$. The limited evidence for systematic gender patterns is in line with the meta-analytic findings of Degner \& Dalege (2013), who did not find any indication of gender match effects.

[Table 3A and 3B]

\section{Mediation Model of Parent-Child Similarity in Ideology and Prejudice}

In a next step, we investigated whether parent-child similarity in RWA and SDO underlies parent-child similarity in prejudice. For each of the specific and common prejudice components, we tested a path model, using Mplus (version 7.3, Muthén \& Muthén, 1998-2014), in which parental RWA and SDO were entered as the predictor variables, followed by child RWA, child SDO, and the parental prejudice component as mediators, while the corresponding prejudice component of the children was included as the criterion variable (see Figure 1). Gender, education track, parental education level, discussion at home and political interest were again included as control variables.

Consistent with previous research (e.g., Duriez \& Soenens, 2009), the results showed that parental RWA and SDO were significantly related to child RWA $\left(\beta_{\text {mother }}=.29, p<.001\right.$; 
$\left.\beta_{\text {father }}=.25, p<.001\right)$ and SDO $\left(\beta_{\text {mother }}=.13, p<.001 ; \beta_{\text {father }}=.13, p<.001\right)$. Moderation analyses revealed that parent-child similarity in ideological attitudes did not show significant gender-match effects. ${ }^{4}$ More importantly, we found supporting evidence for the hypothesized mediation model (Figure 1) when it comes to the common component of prejudice. For both the mothers (see Table 4A) and fathers (see Table 4B), parental RWA and SDO were significantly indirectly related to the common component of child prejudice via the common component of parental prejudice and, respectively, child RWA and SDO. Testing this mediation model with the general prejudice factor instead of the common component also confirmed all paths from the mediation model (see last columns of Table 4A and 4B).

In contrast, this mediation model did not hold for the specific components in prejudice. Indeed, although a few weak significant indirect relations between parental ideology and specific components in prejudice were observed, these relations did not generally translate into meaningful, significant total effects between the variables, except in one case; we found a significant total effect of parental RWA on the specific component of child anti-immigrant prejudice, which partly proceeded through child RWA (for both mothers and fathers) and the specific component of parental anti-immigrant prejudice (for mothers). Overall, the results of the mediation analyses corroborated Hypothesis 2 by showing that the intergenerational similarity in the common component of prejudice was partly rooted in the intergenerational similarity in ideological attitudes.

[Table 4A and 4B]

\section{The Moderating Role of Political Discussion}

The third aim of this paper was to investigate the moderating effect of political discussion at home on the parent-child similarity relations of prejudice and ideological attitudes. First, we conducted a series of regression analyses to test the effects of each of the common and 
specific components of parental prejudice, discussion at home (centered), and their interaction term (the multiplied centered scores) on the corresponding common and specific prejudice components of the children. Again, gender, education track, parental education, and political interest were included as control variables. The results of these moderation analyses are presented in the bottom lines of Table $3 \mathrm{~A}$ and $3 \mathrm{~B}$.

As expected, discussion at home had a significant moderating effect on the intergenerational similarity of the common component of prejudice. Simple slope analyses indicated that the common prejudice components of both the mothers and fathers were more strongly related to the common prejudice components of the children among children reporting higher levels $(M+1 \mathrm{SD})$ of political discussion, with $\beta$ s ranging from $\beta=.24, p<.001$ to $\beta=$ $.38, p<.001$, than among children reporting lower levels (M -1SD) of political discussion, with $\beta$ s ranging from $\beta=.08, p<.05$ to $\beta=.21, p<.001$. Moderation analyses with the general prejudice factor confirmed these results. Figure 2 presents the observed interaction pattern showing the relationship between the general prejudice factor of mothers and children (Panel A) and fathers and children (Panel B), moderated by political discussion. Importantly, no significant moderation effect of political discussion was found for any of the specific forms of prejudice, (see Tables 3A and 3B), except for mother-child correspondence in sexism. Similar to the moderation effect for the common prejudice components, a stronger mother-child similarity in the specific sexism component was found for children reporting higher ( $v s$ lower) levels of political discussion at home.

\section{[Figure 2]}

We conducted similar moderation analyses to test whether parent-child similarity in RWA and SDO was facilitated by political discussion. Results confirmed a moderation effect of political discussion on parent-child similarity in RWA, $\beta_{\text {mother }}=.07,, p=.007 ; \beta_{\text {father }}=.06, p$ $=.008$ (see Figure 3), revealing stronger similarity associations among children reporting higher 
levels $(M+1 \mathrm{SD})$ of political discussion, $\beta_{\mathrm{mother}}=.37, p<.001$ and $\beta_{\mathrm{father}}=.31, p<.001$, than among adolescents reporting lower levels $(M-1 \mathrm{SD})$ of political discussion, $\beta_{\text {mother }}=.24, p<$ .001 and $\beta_{\text {father }}=.18, p<.001$. The interaction effect between parental SDO and political discussion on child SDO was non-significant for the mother-child association in $\mathrm{SDO}, \beta_{\mathrm{mother}}=$ $.01, p=.624$, and marginally significant for the father-child association in SDO, $\beta_{\text {father }}=.04, p$ $=.089$, indicating a somewhat stronger association among children reporting higher levels of political discussion, $\beta_{\text {father }}=.17, p<.001$, than among children reporting lower levels of political discussion, $\beta_{\text {father }}=.09, p=.01$.

[Figure 3]

In line with Hypothesis 3, the moderation analyses confirmed that more frequent discussions about social and political issues with mother and father were associated with stronger parent-child similarity in the common component of prejudice and with stronger parent-child similarity in RWA. A similar facilitating tendency of political discussion was observed for the child-father similarity in SDO, but not for the child-mother similarity association in SDO.

\section{Discussion}

This study combined the individual difference and developmental perspective into the debate on prejudice acquisition by investigating parent-child similarity in prejudice, the explanatory power of similarity in ideological attitudes, and the moderating role of discussion at home. Unique to our study was the consideration of different types of prejudice which enabled us to distinguish between common and specific components of prejudice and to evaluate the degree of intergenerational similarity in these components. In the following 
sections, we first elaborate on the three main findings of the present study and then discuss potential limitations of our research and provide ideas for future studies.

\section{Major Findings}

As expected (Degner \& Dalege, 2013), the zero-order correlations indicated that parents (both fathers and mothers) and children resembled to each other in different types of intergroup attitudes, including anti-immigrant prejudice, anti-gay bias, sexism, and anti-Muslim prejudice. This consistent pattern of significant correlations across different prejudice types serves as a first indication that children have adopted similar attitudes towards all types of outgroups which reflects intergenerational similarity in generalized prejudicial tendencies.

Indeed, directly testing this hypothesis (Hypothesis 1) confirmed that parents and children showed substantial parent-child similarity for the common component of prejudice, whereas parent-child similarity in the specific components of prejudice was clearly less pronounced. In other words, parents and children resembled each other in their general tendency to dislike outgroups, but only weakly resembled each other in their dislike of specific target groups after controlling for the shared variance with other prejudice types. This finding was quite robust because (1) it remained stable even when controlling for the shared socio-economic environment of family members, and (2) it was consistently observed for both mother-child and father-child associations. Moreover, we operationalized the common core of prejudice as the variance shared between one prejudice measure with all other prejudice measures (via residual regression analysis) and as the variance shared between all types of prejudice simultaneously (via PCA). Highly similar results were obtained with both operationalizations of generalized prejudice, supporting our hypothesis.

Interestingly, however, even when controlling for the shared variance between the different prejudice types, significant parent-child similarity in target-specific prejudice could 
still be observed, particularly with respect to anti-gay prejudice. This latter finding suggests that intergenerational similarity in anti-gay bias may partly rely on different, outgroup-specific genetic or socialization mechanisms, whereas parent-child similarity in the other types of prejudice is largely captured by the similarity in generalized prejudice, suggesting similar genetic or socialization mechanisms (Degner \& Dalege, 2013). However, only tentative conclusions can be made when comparing the strength of the relations between the targetspecific parent-child similarity because the specific components are dependent on the strength of the interrelations of the prejudice scales (see Lynam, Hoyle, \& Newman, 2006). The results of some specific components might have been deflated for strongly inter-correlated prejudice measures (e.g., anti-immigrant and anti-Muslim prejudice) or inflated when a scale showed somewhat weaker correlations with other prejudice scales (e.g., anti-gay prejudice).

We also found significant parent-child similarity in ideological attitudes (RWA and SDO), thereby corroborating previous research (Chatard \& Selimbegovic, 2008; Dhont \& Van Hiel, 2009; Duriez et al. 2008). More importantly, the ideological attitudes of the parents were indirectly related to the common, but not to the specific prejudice components of the children. Specifically, parental ideological attitudes were associated with children's common component of prejudice via prejudice of the parents and via the ideological attitudes of the children. Hence, supporting Hypothesis 2, the parent-child correspondence in the common component was partly explained by a more deeply rooted similarity in ideological attitudes. RWA and SDO are considered as relatively stable individual difference variables and are unlikely to show major changes after the formative phase of adolescence (Altemeyer, 1996; Duriez et al, 2008; Kteily, Sidanius, \& Levin, 2011). Therefore, it can be speculated that family influence via ideology has an enduring impact on children and their value patterns, although different underlying mechanisms might be at play during different stages in life: socialization practices during 
adolescence and genetic heritability in adulthood as suggested by behavioral genetic studies (Eaves et al., 1997; Eaves et al., 2008; Hatemi et al., 2009).

Finally, we tested the presumed reinforcing effect of political and social discussions at home on the parent-child similarity in prejudice (Hypothesis 3). Children who discuss political and social issues more often with their parents, showed a stronger correspondence in the common components of prejudice as well as a stronger correspondence in ideological attitudes, particularly with respect to RWA. Family discussions thus indeed related to stronger parentchild similarity. This moderating influence may work in two ways: (1) directly, because when parents discuss certain topics on a regular basis, children can actively adopt these attitudes, and (2) indirectly, because by discussing certain topics, parents show a strong commitment to that attitude and increase the attitude salience and visibility for the children. This way, parents encourage their children to identify with their own social and political predispositions (Jennings et al., 2009). Furthermore, the finding that discussions on general political and social issues at home strengthened the parent-child similarity in broad social-ideological attitudes and the common component of prejudice suggests that frequency of discussion at home can be considered characteristic of a positive and open parent-child relationship. An open communication style between parents and children may have increased parent-child similarity (Kinder \& Kam, 2010), even though this may also imply an increase or polarization of negative outgroup attitudes. However, our cross-sectional data does not allow for substantiating any such causal claims and longitudinal studies are needed to test if family politicization increases parent-child similarity in political and intergroup attitudes across time or, alternatively, if family members holding more similar attitudes are more inclined to discuss their opinions with each other.

Taken together, the results highlighted that it is important to consider the shared variance between different types of prejudice when studying the development of prejudice during 
adolescence. With regard to the debate on the structure of prejudice, the results supported Akrami and colleagues (2011) who argued that particularly common, rather than specific, structures of prejudice are driven by individual difference variables, in our case ideological attitudes. Yet the results extended previous findings in an important way by demonstrating that especially this common component was sensitive to family influences. Associations between one's ideological attitudes and the common component of prejudice were connected to these same associations observed among one's parents. Therefore, the current findings concur with Degner and Dalege's suggestion (2013) that "although children might be less influenced by parent's specific attitudes toward specific social groups, they nevertheless adopt a similar ideology and similar attitudes toward outgroups in general" (p. 18). At the same time, our findings emphasized that despite the importance of individual differences in explaining the common component of prejudice this did not preclude the influence of situational factors, and familial factors in particular. More specifically, the moderating influence of discussion at home on the common prejudice component is hard to reconcile with the idea of Akrami et al. (2011) that mainly the specific components of prejudice are dependent on situational factors.

Finally, how can these parent-child similarities in ideological attitudes and prejudice be interpreted in light of the growing body of evidence from twin and adoption studies illustrating the heritability of these variables (e.g., Lewis \& Bates, 2014; Lewis et al., 2014; Ludeke et al., 2013; McCourt et al., 1999)? With the current research design, we cannot estimate what proportion of the variance in parent-child similarity can be attributed to genetic influence and what proportion can be attributed to shared or unique environmental influences. However, the moderating role of political discussion facilitating parent-child similarity, may indicate that at least a portion of the variance can be explained by social learning mechanisms and that children tend to "imitate, internalize, and reproduce what parents say or do" (Kinder \& Kam, 2010, p. 61). Such interpretation is consistent with behavioral genetic studies relying on samples of both 
adolescent and adult twins showing that shared environmental influences are especially relevant for attitude formation during adolescence, but only play a minor role once people enter adulthood (Eaves et al., 1997; Hatemi et al., 2009). Indeed, the children in our study were on average between 16 and 17 years old and were all living with their parents, meeting the right conditions where the greatest socialization influences can be expected. Yet once these adolescents have entered adulthood and are no longer living with their parents, discussions about political and societal topics between parents and children along with other family influences likely decrease so that facilitating effects of political discussion might no longer be detected.

\section{Limitations and Future Directions}

Before closing, some limitations of the current study should be mentioned. As mentioned earlier when discussing the effects of political discussion, the cross-sectional nature of our data does not allow for drawing causal conclusions. This limitation also applies to the causal direction of parent-child associations. From a socialization perspective, it could be argued that the shared environmental influence for political and intergroup attitudes works in a bidirectional way between parents and children. The little research that is available, however, has indicated that parents are more successful in influencing their children than the other way around (Rodríguez-García \& Wagner, 2009; Vollebergh et al., 2001). Furthermore, specific family characteristics and the dynamic interactions between all members likely shape different types of family climates, classifying them as tolerant or intolerant towards outgroups. Some families may also 'specialize' in one type of prejudice by showing particularly strong negative attitudes toward one outgroup (e.g. ethnic outgroups) while being relatively tolerant towards other outgroups (e.g. LGBTs). Focusing on the role of such socialization factors would be particularly valuable when using longitudinal research designs and in combination with twin 
study designs to investigate how these factors are related to the proportion of the similarity between twins explained by shared environment.

It should also be acknowledged that the available scales for RWA and SDO were suboptimal given the limited number of items. The relatively low reliability of the SDO-scale may partly explain why weaker relations were obtained for SDO compared to RWA, possibly underestimating the actual associations. Overall, including the ideological attitudes in the analyses only slightly decreased the strength of the parent-child similarity in the common components of prejudice, leaving room for different mechanisms underlying parent-child similarity in ideology and prejudice. More specifically, ideological and intergroup attitudes may have both common and unique genetic links (e.g., Lewis et al., 2014) and are likely influenced by both common and unique contextual features. The degree of relative economic deprivation, levels of intergroup contact, and living in the same neighborhood are, for instance, other important contextual mechanisms in need of further investigation (see Davidov, Thörner, Schmidt, Gosen, \& Wolf, 2011; Dhont \& Van Hiel, 2012; Kinder \& Kam, 2011; Meeusen, 2014a).

Finally, as studying prejudice is always embedded in a specific context, research in different intergroup contexts and focusing on a wider range of outgroups is required to be able to generalize the current findings. Also, the development of separate indices of specific and generalized prejudice would be very helpful in attempts to replicate and generalize previous research findings.

\section{Conclusion}

Using a large representative sample from Belgium, this study demonstrated that levels of prejudice are family dependent: children with prejudiced parents were more likely to be prejudiced themselves. This is particularly true with respect to parents' and children's general dislike of outgroups which were associated with parent-child similarity in ideological attitudes. 
Finally, discussing politics at home significantly facilitated the correspondence between parents and children, suggesting that children have actively learned parental predispositions instead of blindly copying their attitudes and behaviors. 


\section{Acknowledgements}

Cecil Meeusen is grateful to the Research Foundation - Flanders (FWO, Belgium) for the PhD fellowship, which made it possible to contribute to this article. Part of this paper was prepared when Kristof Dhont was a post-doctoral fellow also supported by the Research Foundation Flanders (FWO, Belgium). 


\section{References}

Aboud, F. E., \& Doyle, A.-B. (1996). Parental and peer influences on children's racial attitudes. International Journal of Intercultural Relations, 20(3-4), 371-383.

Adorno, T. W., Frenkel-Brunswick, E., Levinson, D. J., \& Stanford, R. N. (1950). The authoritarian personality. New York: Harper \& Row.

Akrami, N., Ekehammar, B., \& Bergh, R. (2011). Generalized prejudice: Common and specific components. Psychological Science, 22(1), 57-59.

Allport, G. W. (1954). The nature of prejudice. Reading, MA: Addison-Wesley.

Altemeyer, B. (1981). Right-wing authoritarianism. Winnipeg: University of Manitoba Press.

Altemeyer, B. (1996). The authoritarian specter. Cambridge, MA: Harvard University Press.

Amato, P., \& Booth, A. (1995). Changes in gender role attitudes and perceived marital quality. American Sociological Review, 60(1), 58-66.

Bandura, A. (1977). Social Learning Theory. Englewood Cliffs: Prentice Hall.

Boonen, J., Meeusen, C., Quintelier, E. (2014). The link between social attitudes and voting propensities: Attitude-vote consistency among adolescents in Belgium. Electoral Studies, 36(4), 81-93.

Branch, C., \& Newcombe, N. (1986). Racial attitude development among young Black children as a function of parental attitudes: A longitudinal and cross-sectional study. Child Development, 57(3), 712-721.

Chatard, A., \& Selimbegovic, L. (2008). The intergenerational transmission of social dominance: A three-generation study. European Journal of Personality, 55(1), 541551.

Cunningham, W. A., Nezlek, J. B., \& Banaji, M. R. (2004). Implicit and explicit ethnocentrism: Revisiting the ideologies of prejudice. Personality and Social Psychology Bulletin, 30(10), 1332-1346. 
Davidov, E., Thörner, S., Schmidt, P., Gosen, S., \& Wolf, C. (2011). Level and change of group-focused enmity in Germany: Unconditional and conditional latent growth curve models with four panel waves. Advances in Statistical Analysis, 95(4), 481-500.

Degner, J., \& Dalege, J. (2013). The apple does not fall far from the tree, or does it? A metaanalysis of parent-child similarity in intergroup attitudes. Psychological Bulletin, 139(6), 1270-1304

Dhont, K., \& Hodson, G. (2014a). Does lower cognitive ability predict greater prejudice? Current Directions in Psychological Science, 23(6), 454-459.

Dhont, K., \& Hodson, G. (2014b). Why do right-wing adherents engage in more animal exploitation and meat consumption? Personality and Individual Differences, 64, 1217.

Dhont, K., Hodson, G., Costello, K., \& MacInnis, C. C. (2014). Social dominance orientation connects prejudicial human-human and human-animal relations. Personality and Individual Differences, 61-62, 105-108.

Dhont, K., Roets, A., \& Van Hiel, A. (2013). The intergenerational transmission of need for closure underlies the transmission of authoritarianism and anti-immigrant prejudice. Personality and Individual Differences, 54(6), 779-784

Dhont, K., \& Van Hiel, A. (2012). Intergroup contact buffers against the intergenerational transmission of authoritarianism and racial prejudice. Journal of Research in Personality, 46(2), 231-234.

Duckitt, J. (2001). A dual-process cognitive-motivational theory of ideology and prejudice. Advances in Experimental Social Psychology, 33, 41-113.

Duckitt, J., Wagner, C., du Plessis, I., \& Birum, I. (2002). The psychological bases of ideology and prejudice: Testing a dual process model. Journal of Personality and Social Psychology, 83(1), 75-93. 
Duriez, B., \& Soenens, B. (2009). The intergenerational transmission of racism: The role of right-wing authoritarianism and social dominance orientation. Journal of Research in Personality, 43(5), 906-909.

Duriez, B., Soenens, B., \& Vansteenkiste, M. (2007). In search of the antecedents of adolescent authoritarianism: The relative contribution of parental goal promotion and parenting style dimensions. European Journal of Personality, 21(4), 507-527.

Duriez, B., Soenens, B., \& Vansteenkiste, M. (2008). The intergenerational transmission of authoritarianism: The mediating role of parental goal promotion. Journal of Research in Personality, 42(3), 622-642.

Eaves, L. J. \& Hatemi, P. K. (2008). Transmission of attitudes toward abortion and gay rights: Parental socialization or parental mate selection? Behavior Genetics, 38(3), 247-256.

Eaves, L. J., Hatemi, P. K., Prom-Womley, E. C., \& Murrelle, L. (2008). Social and genetic influences on adolescent religious attitudes and practices, Social Forces, 86(4), 16211646.

Eaves, L. J., Martin, N., Heath, A., Schieken, R., Meyer, J., Silberg, J., ... Corey, L. (1997). Age changes in the cause of individual differences in conservatism. Behavior Genetics, 27(2), 121-124.

Ekehammar, B., \& Akrami, N. (2003). The relation between personality and prejudice: A variable- versus a person-centred approach. European Journal of Personality, 17(6), 449-464.

Ekehammar, B., Akrami, N., Gylje, M., Zakrisson, I. (2004). What matters most to prejudice: Big Five personality, social dominance orientation or right-wing authoritarianism? European Journal of Personality, 18(6), 463-482. 
Hatemi, P. K., Funk, C. L., Medland, S. E., Maes, H. M., Silberg, J., Martin, N., \& Eaves, L. J. (2009). Genetic and environmental transmission of political attitudes over a life time. The Journal of Politics, 71(3), 1141-1156.

Hodson, G. \& Dhont, K. (2015). The person-based nature of prejudice: Individual difference predictors of intergroup negativity. (manuscript revised and resubmitted)

Hodson, G., Hogg, S. M., \& MacInnis, C. C. (2009). The role of "dark personalities" (narcissism, Machiavellianism, psychopathy), Big Five personality factors, and ideology in explaining prejudice. Journal of Research in Personality, 43(4), 686-690.

Hooghe, M., \& Boonen, J. (2015). The intergenerational transmission of voting intentions in a multiparty setting: An analysis of voting intentions and political discussion among 15year old adolescents and their parents in Belgium. Youth \& Society, 47(1), 125-147.

Hooghe, M., \& Meeusen, C. (2012). Homophobia and the transition to adulthood: A three year panel study among Belgian late adolescents and young adults, 2008-2011. Journal of Youth and Adolescence, 41(9), 1197-1207.

Hooghe, M., Quintelier, E., Meeusen, C., Verhaegen, S., Boonen, J., \& Smets, A. (2013). Parent-Child Socialization Study (PCSS) 2012-2013. Technical Report (p. 50). Leuven.

Jennings, M. K., Stoker, L., \& Bowers, J. (2009). Politics across generations: Family transmission reexamined. The Journal of Politics, 71(3), 782-799.

Kinder, D. R., \& Kam, C. D. (2010). Us against them. Ethnocentric foundations of American opinion. Chicago: The University of Chicago Press.

Kteily, N. S., Ho, A., \& Sidanius, J. (2012). Hierarchy in the mind: The predictive power of social dominance orientation across social contexts and domains. Journal of Experimental Social Psychology, 48(2), 543-549. 
Kteily, N. S., Sidanius, J., \& Levin, S. (2011). Social dominance orientation: Cause or "mere effect"? Evidence for SDO as a causal predictor of prejudice and discrimination against ethnic and racial outgroups. Journal of Experimental Social Psychology, 47(1), $208-214$.

Lewis, G. J., \& Bates, T. C. (2010). Genetic evidence for multiple biological mechanisms underlying ingroup favoritism. Psychological Science, 21, 1623-1628.

Lewis, G. J., \& Bates, T. C. (2014). Common heritable effects underpin concerns over norm maintenance and in-group favoritism: Evidence from genetic analyses of right-wing authoritarianism and Traditionalism. Journal of Personality, 82, 297-309.

Lewis, G. J., Kandler, C., \& Riemann, R. (2014). Distinct heritable influences underpin ingroup love and out-group derogation. Social Psychological and Personality Science, 5, 407-413.

Ludeke, S., Johnson, W., \& Bouchard, T. J. J. (2013). “'Obedience to traditional authority:” A heritable factor underlying authoritarianism, conservatism and religiousness. Personality and Individual Differences, 55(4), 375-380.

Lynam, D. R., Hoyle, R. H., \& Newman, J. P. (2006). The perils of partialling. Cautionary tales from aggression and psychopathy. Assessment, 13(3), 328-342.

McCourt, K., Bouchard, T. J., Lykken, D. T., Tellegen, A., \& Keyes, M. (1999). Authoritarianism revisited: genetic and environmental influences examined in twins reared apart and together. Personality and Individual Differences, 27(5), 985-1014.

McFarland, S. (2010). Authoritarianism, social dominance, and other roots of generalized prejudice. Political Psychology, 31(3), 453-477.

Meeusen, C. (2014a). The parent-child similarity in cross-group friendship and antiimmigrant prejudice: A study among 15-year old adolescents and both their parents in Belgium. Journal of Research in Personality, 50(1), 46-55. 
Meeusen, C. (2014b). The intergenerational transmission of environmental concern: The influence of parents and communication patterns within the family. Journal of Environmental Education, 45(2), 77-90.

Mplus (Version 7.3) [Computer Software] by Muthèn, B. O. and Muthèn, L. K.

O’Bryan, M., Fishbein, H., \& Ritchey, P. (2004). Intergenerational transmission of prejudice, sex role stereotyping, and intolerance. Adolescence, 39(155), 407-426.

OECD. (2013). International Migration Outlook 2013. Paris: OECD Publishing.

Olson, J. M., Vernon, P. a, Harris, J. a, \& Jang, K. L. (2001). The heritability of attitudes: a study of twins. Journal of Personality and Social Psychology, 80(6), 845-860.

Orey, B. D., \& Park, H. (2012). Nature, nurture, and ethnocentrism in the Minnesota Twin Study. Twin Research and Human Genetics, 15(1), 71-73.

Peterson, B. E., \& Duncan, L. E. (1999). Authoritarianism of parents and offspring: Intergenerational politics and adjustment to college. Journal of Research in Personality, 33(4), 494-513.

Pratto, F., Cidam, A., Stewart, A. L., Zeineddine, F. B., Aranda, M., Aiello, A., ... Henkel, K. E. (2013). Social dominance in context and in individuals: Contextual moderation of robust effects of social dominance orientation in 15 languages and 20 countries. Social Psychological and Personality Science, 4(5), 587-599.

Pratto, F., Sidanius, J., Stallworth, L. M., \& Malle, B. F. (1994). Social dominance orientation: A personality variable predicting social and political attitudes. Journal of Personality and Social Psychology, 67(4), 741-763.

Roets, A. \& Van Hiel, A. (2011). Allport's prejudiced personality today: Need for closure as the motivated cognitive basis of prejudice. Current Directions in Psychological Science, 20(6), 349-354. 
Roets, A., Van Hiel, A., \& Dhont, K. (2012). Is sexism a gender issue? A motivated social cognition perspective on men's and women's sexist attitudes toward the own and other gender. European Journal of Personality, 26(3), 350-359.

Rodríguez-Garcia, J.-M., \& Wagner, U. (2009). Learning to be prejudiced: A test of unidirectional and bidirectional models of parent-offspring socialization. International Journal of Intercultural Relations, 33(6), 516-523.

Savelkoul, M., Scheepers, P., Tolsma, J., \& Hagendoorn, L. (2010). Anti-Muslim attitudes in The Netherlands: Tests of contradictory hypotheses derived from ethnic competition theory and intergroup contact theory. European Sociological Review, 27(6), 741-758.

Schafer, J., \& Graham, J. (2002). Missing data: our view of the state of the art. Psychological Methods, 7(2), 147-177.

Sibley, C. G., \& Duckitt, J. (2008). Personality and prejudice: A meta-analysis and theoretical review. Personality and Social Psychology Review, 12(3), 248-279.

Sidanius, J., \& Pratto, F. (1999). Social Dominance: An intergroup theory of social hierachy and oppression. Cambridge: Cambridge University Press.

Van Hiel, A., Cornelis, I., \& Roets, A. (2007). The intervening role of social worldviews in the relationship between the Five-Factor Model of personality and political ideology. European Journal of Personality, 21(2), 131-148.

Van Hiel, A., Pandelaere, M., \& Duriez, B. (2004). The impact of need for closure on conservative beliefs and racism: Differential mediation by authoritarian submission and authoritarian dominance. Personality and Social Psychology Bulletin, 30(7), 824837.

Vollebergh, W., Iedema, J., \& Raaijmakers, Q. A. (2001). Intergenerational transmission and the formation of cultural orientations in adolescence and young adulthood. Journal of Marriage and Family, 63(4), 1185-1198. 
Wright, L. W., Adams, H. E., \& Bernat, J. (1999). Development and validation of the homophobia scale. Journal of Psychopathology and Behavioral Assessment, 21(4), 337347.

Zick, A., Wolf, C., Küpper, B., Davidov, E., Schmidt, P., \& Heitmeyer, W. (2008). The syndrome of group-focused enmity: The interrelation of prejudices tested with multiple cross-sectional and panel data. Journal of Social Issues, 64(2), 363-384. 


\section{Footnotes}

${ }^{1}$ By deleting the respondents with another ethnic background from the data, we simultaneously also removed all Muslim respondents. Unfortunately, we did not have any indication of the sexual orientation of the respondents. As a consequence, we could not delete lesbian, gay, and bisexual respondents from the sample.

${ }^{2}$ Although the reliability coefficients of the SDO scale were lower than optimal, they were comparable to those reported in previous research that demonstrated the high predictive validity of short SDO scales (e.g., Asbrock, Christ, Duckitt, \& Sibley, 2012; Hooghe \& Meeusen, 2012; Pratto et al., 2013).

${ }^{3}$ All 18 correlations were significant, $p$ s $<.001$, except for the correlation between mother's anti-Muslim and anti-gay prejudice. The relatively high correlations between antiimmigrant and anti-Muslim prejudice suggest that respondents have similar attitudes toward ethnic and religious minorities. This is not surprising as in the Belgian context immigrants often have Islamic roots (OECD, 2013).

${ }^{4}$ Results for gender patters of the ideological attitudes: For mothers: $\beta_{\text {RWA }}{ }^{\text {gender }}=.02, p$ $=.49 ; \beta_{\mathrm{SDO}} *$ gender $=-.03, p=.38 ;$ For fathers: $\beta_{\mathrm{RWA}} *_{\text {gender }}=.07, p=.07 ; \beta_{\mathrm{SDO}} *$ gender $=-.02, \mathrm{p}=$ 66 . 
Table 1. Descriptive statistics and correlations between different prejudice types and between prejudice types and ideological attitudes and political discussion

\begin{tabular}{|c|c|c|c|c|c|c|c|c|c|c|c|c|c|c|c|}
\hline & \multicolumn{3}{|c|}{ Anti-immigrant prejudice } & \multicolumn{3}{|c|}{ Anti-Muslim prejudice } & \multicolumn{3}{|c|}{ Anti-gay prejudice } & \multicolumn{3}{|l|}{ Sexism } & \multicolumn{3}{|c|}{ Descriptives } \\
\hline & Child & Mother & Father & Child & Mother & Father & Child & Mother & Father & Child & Mother & Father & Range & Mean & SD \\
\hline \multicolumn{16}{|l|}{ Prejudice } \\
\hline \multicolumn{16}{|c|}{ Anti-immigrant } \\
\hline Child & - & $.33 * * *$ & $.33 * * *$ & $.73^{* * *}$ & $.29 * * *$ & $.30 * * *$ & $.29 * * *$ & $.07 * *$ & $.15^{* * *}$ & $.37 * * *$ & $.17 * * *$ & $.14 * * *$ & $0-3$ & 1.72 & .58 \\
\hline Mother & & - & $.51 * * *$ & $.29 * * *$ & $.72 * * *$ & $.44 * * *$ & .03 & $.08 * * *$ & $.17 * * *$ & $.16^{* * *}$ & $.30 * * *$ & $.21 * * *$ & $0-3$ & 1.72 & .54 \\
\hline Father & & & - & $.29 * * *$ & $.43 * * *$ & $.77 * * *$ & $.07 * *$ & $.06^{*}$ & $.24 * * *$ & $.18^{* * *}$ & $.19 * * *$ & $.33 * * *$ & $0-3$ & 1.78 & .57 \\
\hline \multicolumn{16}{|l|}{ Anti-Muslim } \\
\hline Child & & & & - & $.29 * * *$ & $.28 * * *$ & $.27 * * *$ & .04 & $.11 * * *$ & $.31 * * *$ & $.09 * * *$ & $.10 * * *$ & $0-3$ & 1.58 & .65 \\
\hline Mother & & & & & - & $.44 * * *$ & .03 & .03 & $.12 * * *$ & $.12 * * *$ & $.17 * * *$ & $.15^{* * *}$ & $0-3$ & 1.68 & .45 \\
\hline Father & & & & & & - & .05 & .03 & $.21 * * *$ & $.13 * * *$ & $.12 * * *$ & $.27 * * *$ & $0-3$ & 1.74 & .55 \\
\hline \multicolumn{16}{|l|}{ Anti-gay } \\
\hline Child & & & & & & & - & $.22 * * *$ & $.20 * * *$ & $.45^{* * *}$ & $.14 * * *$ & $.11 * * *$ & $0-3$ & 0.77 & .57 \\
\hline Mother & & & & & & & & - & $.31 * * *$ & $.15^{* * *}$ & $.31 * * *$ & $.17 * * *$ & $0-3$ & 0.44 & .56 \\
\hline Father & & & & & & & & & - & $.16^{* * *}$ & $.17 * * *$ & $.35^{* * *}$ & $0-3$ & 0.68 & .58 \\
\hline \multicolumn{16}{|l|}{ Sexism } \\
\hline Child & & & & & & & & & & - & $.24 * * *$ & $.19 * * *$ & $0-3$ & 1.05 & .57 \\
\hline
\end{tabular}




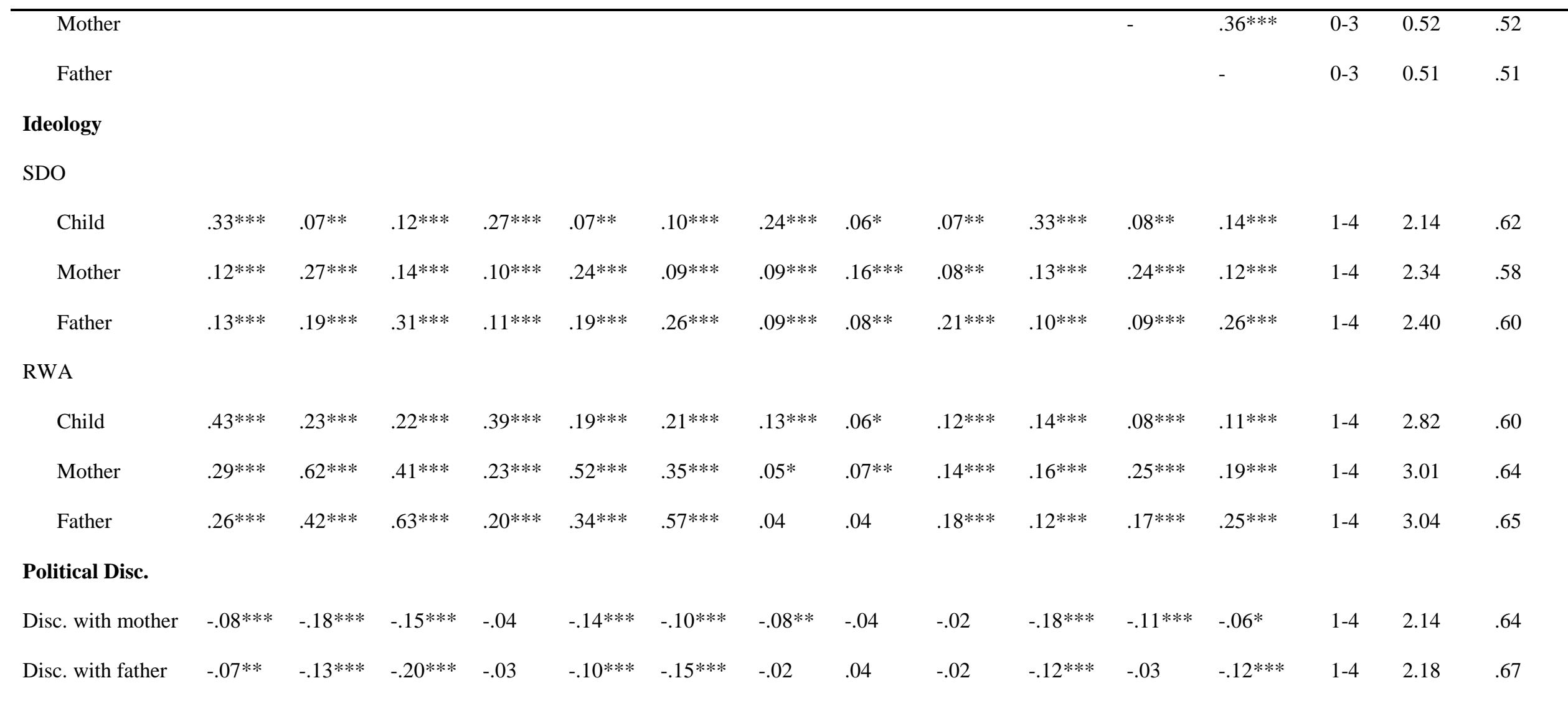

Note. Values in bold represent relations between prejudice measures of parents and children for corresponding prejudice types, indicating parentchild similarity. Disc. $=$ Discussion. $* p<.05 ; * * p<.01 ; * * p<.001$. 
Table 2. Correlations between ideological attitudes and between ideological attitudes and political discussion

\begin{tabular}{|c|c|c|c|c|c|c|}
\hline & SDO & & & RWA & & \\
\hline & Child & Mother & Father & Child & Mother & Father \\
\hline \multicolumn{7}{|l|}{ SDO } \\
\hline Child & - & & & & & \\
\hline Mother & $.14 * * *$ & - & & & & \\
\hline Father & $.15 * * *$ & $.22 * * *$ & - & & & \\
\hline \multicolumn{7}{|l|}{ RWA } \\
\hline Child & $.21 * * *$ & $.11 * * *$ & $.11 * * *$ & - & & \\
\hline Mother & $.10 * * *$ & $.28 * * *$ & $.19 * * *$ & $.31 * * *$ & - & \\
\hline Father & $.12 * * *$ & $.17 * * *$ & $.29 * * *$ & $.26 * * *$ & $.49 * * *$ & - \\
\hline \multicolumn{7}{|l|}{ Political disc. } \\
\hline Disc. with mother & -.04 & $-.10 * * *$ & $-.06^{*}$ & .01 & $-.17 * * *$ & $-.12 * * *$ \\
\hline Disc. with father & -.04 & $.05^{*}$ & $-.08 * *$ & .02 & $-.15 * * *$ & $-.17 * * *$ \\
\hline
\end{tabular}

$\overline{\text { Note. Values in bold represent relations between ideology measures of parents and children for }}$ corresponding ideology attitudes, indicating parent-child similarity. Disc. $=$ Discussion.

$* p<.05 ; * * p<.01 ; * * * p .001$. 
Table 3A. Regression results of specific and common prejudice components of the mothers predicting corresponding prejudice components of children

\begin{tabular}{|c|c|c|c|c|c|c|c|c|c|}
\hline & \multicolumn{2}{|c|}{ Anti-immigrant } & \multicolumn{2}{|c|}{ Anti-Muslim } & \multicolumn{2}{|l|}{ Anti-gay } & \multicolumn{2}{|l|}{ Sexism } & \multirow{2}{*}{$\begin{array}{l}\text { General } \\
\text { prejudice } \\
\text { factor }\end{array}$} \\
\hline & Specific & Common & Specific & Common & Specific & Common & Specific & Common & \\
\hline Parental prejudice $^{\mathrm{a}}$ & $.09 * * *$ & $.28 * * *$ & $.09 * * *$ & $.28 * * *$ & $.17 * * *$ & $.17 * * *$ & $.12 * * *$ & $.23 * * *$ & $.30 * * *$ \\
\hline Political interest & -.03 & $-.07 * *$ & .00 & $-.06^{*}$ & -.03 & $-.10 * * *$ & $-.06^{*}$ & $-.08 * * *$ & $-.09 * * *$ \\
\hline Political discussion & .01 & .03 & .03 & .02 & .01 & $-.05 *$ & $-.08 * *$ & .00 & .00 \\
\hline Gender (ref. Female) & .02 & $.30 * * *$ & .03 & $.28 * * *$ & $.33 * * *$ & $.39 * * *$ & $.16^{* * * *}$ & $.46^{* * *}$ & $.42 * * *$ \\
\hline Technical $^{\text {b }}$ & $.09 * *$ & $.09 * * *$ & -.02 & $.13 * * *$ & -.04 & $.13 * * *$ & $.08 * *$ & $.08 * * *$ & $.11 * * *$ \\
\hline Artistic $^{\mathrm{b}}$ & $-.04^{c}$ & -.00 & .04 & -.03 & -.04 & -.03 & -.00 & $-.05^{*}$ & $-.03 *$ \\
\hline Vocational $^{\mathrm{b}}$ & -.02 & .03 & -.01 & .02 & .01 & $.11^{* * *}$ & $.12 * * *$ & $.05^{*}$ & $.06^{*}$ \\
\hline Parental education & $-.09 * *$ & -.03 & -.01 & $-.06 *$ & $.08 * *$ & $-.04^{\mathrm{c}}$ & -.01 & .00 & .00 \\
\hline $\mathrm{R}^{2}$ & .04 & .20 & .01 & .22 & .14 & .28 & .09 & .31 & .33 \\
\hline $\begin{array}{l}\text { Parental prejudice } \\
\text { Discussion }\end{array}$ & $.04^{\mathrm{c}}$ & $.06 * *$ & .03 & $.08 * * *$ & .01 & $.07 * *$ & $.06^{*}$ & $.05^{*}$ & $.06^{* *}$ \\
\hline $\begin{array}{l}\text { Parental prejudice } \\
\text { Gender }\end{array}$ & $-.08 *$ & .00 & -.05 & -.00 & .01 & -.02 & $-.07 *$ & .04 & -.06 \\
\hline
\end{tabular}


${ }^{\mathrm{a}}$ Specific/Common component of parental prejudice; ${ }^{\mathrm{b}}$ Reference category $=$ General education

Note. Entries are standardized coefficients. Interactions were tested in separate models.

${ }^{\mathrm{c}} p<.10 ;{ }^{*} p<.05 ; * * p<.01 ; * * * p<.001$. 
Table 3B. Regression results of specific and common prejudice components of the fathers predicting corresponding prejudice components of

Children

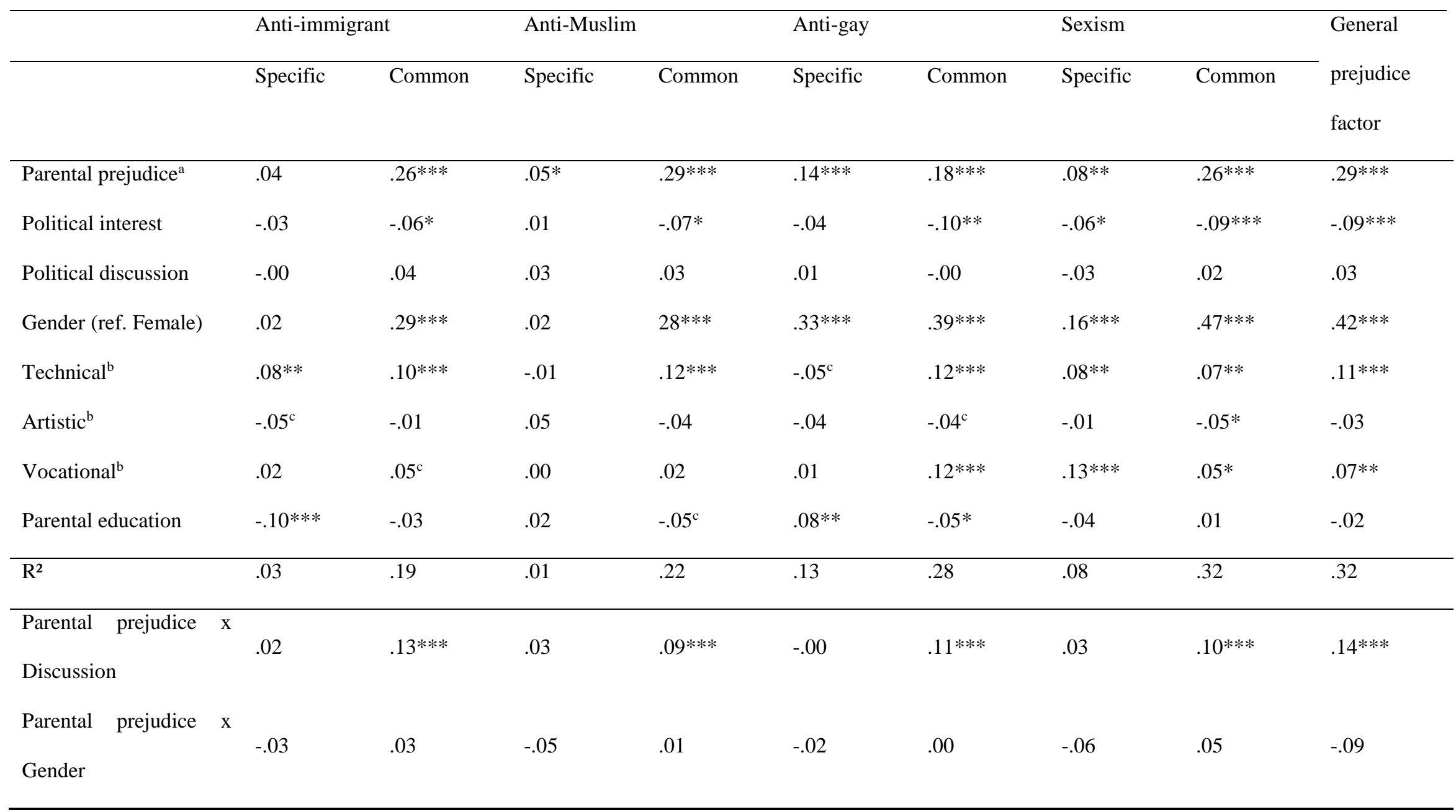


${ }^{\mathrm{a}}$ Specific/Common component of parental prejudice; ${ }^{\mathrm{b}}$ Reference category $=$ General education

Note. Entries are standardized coefficients. Interactions were tested in separate models.

${ }^{\mathrm{c}} p<.10 ;{ }^{*} p<.05 ; * * p<.01 ; * * * p<.001$. 


\begin{tabular}{|c|c|c|c|c|c|c|c|c|c|}
\hline & \multicolumn{2}{|c|}{ Anti-immigrant } & \multicolumn{2}{|c|}{ Anti-Muslim } & \multicolumn{2}{|l|}{ Anti-gay } & \multicolumn{2}{|l|}{ Sexism } & \multirow{2}{*}{$\begin{array}{l}\text { General } \\
\text { prejudice } \\
\text { factor }\end{array}$} \\
\hline & Specific & Common & Specific & Common & Specific & Common & Specific & Common & \\
\hline Parental prejudice $^{\mathrm{a}}$ & $.06^{*}$ & $.24 * * *$ & $.09 * * *$ & $.20 * * *$ & $.17 * * *$ & $.15^{* * *}$ & $.11 * * *$ & $.17 * * *$ & $.24 * * *$ \\
\hline Parental RWA & $.07 *$ & .02 & -.01 & .03 & -.03 & $.09 * * *$ & .03 & .03 & -.00 \\
\hline Parental SDO & -.02 & -.02 & -.00 & -.02 & .03 & .01 & .01 & .01 & -.02 \\
\hline Child RWA & $.15 * * *$ & $.23 * * *$ & $.11 * * *$ & $.29 * * *$ & -.02 & $.11 * * *$ & $-.10 * * *$ & $.18 * * *$ & $.23 * * *$ \\
\hline Child SDO & $.09 * * *$ & $.19 * * *$ & .01 & $.23 * * *$ & .01 & $.25 * * *$ & $.14 * * *$ & $.21 * * *$ & $.25 * * *$ \\
\hline \multicolumn{10}{|l|}{ Indirect effects of } \\
\hline \multicolumn{10}{|l|}{ Parental RWA } \\
\hline Via parental prejudice & $.02 *$ & $.11^{* * *}$ & $.01^{*}$ & $.11 * * *$ & -.00 & $.01 * *$ & -.00 & $.06 * * *$ & $.13 * * *$ \\
\hline Via child RWA & $.05 * * *$ & $.06 * * *$ & $.03 * * *$ & $.09 * * *$ & -.01 & $.03 * * *$ & $-.03 * * *$ & $.05^{* * *}$ & $.07 * * *$ \\
\hline \multicolumn{10}{|l|}{ Parental SDO } \\
\hline Via parental prejudice & .00 & $.03 * *$ & .00 & $.02 * * *$ & $.02 * * *$ & $.02 * * *$ & $.01 * *$ & $.03 * * *$ & $.04 * * *$ \\
\hline Via child SDO & $.01 * *$ & $.03 * * *$ & .00 & $.03 * * *$ & .00 & $.03 * * *$ & $.02 * * *$ & $.03 * * *$ & $.03 * * *$ \\
\hline
\end{tabular}




\begin{tabular}{|c|c|c|c|c|c|c|c|c|c|}
\hline \multicolumn{10}{|l|}{ Total effects of } \\
\hline Parental RWA & $.14 * * *$ & $.19 * * *$ & .03 & $.23 * * *$ & -.04 & $.13 * * *$ & .00 & $.14 * * *$ & $.20 * * *$ \\
\hline Parental SDO & -.01 & .03 & .00 & .03 & $.05^{\mathrm{c}}$ & $.06 * *$ & .04 & $.06 * *$ & $.06^{* *}$ \\
\hline $\mathrm{R}^{2}$ & .08 & .35 & .02 & .36 & .15 & .37 & .11 & .39 & .44 \\
\hline
\end{tabular}

Table 4A. Results of the mediation analyses for the mothers testing parental levels of RWA and SDO as predictors of the common and specific prejudice components of the children via child RWA, child SDO, and the corresponding parental prejudice component 
Specific/Common component of parental prejudice

Note. Entries are standardized coefficients. All models include control variables.

${ }^{c} p<.10 ; * p<.05 ; * * p<.01 ; * * * p<.0$ 
Table 4B. Results of the mediation analyses for the fathers testing parental levels of RWA and SDO as predictors of the common and specific prejudice components of the children via child RWA, child SDO, and the corresponding parental prejudice component 


\begin{tabular}{|c|c|c|c|c|c|c|c|c|c|}
\hline & \multicolumn{2}{|c|}{ Anti-immigrant } & \multicolumn{2}{|c|}{ Anti-Muslim } & \multicolumn{2}{|l|}{ Anti-gay } & \multicolumn{2}{|l|}{ Sexism } & \multirow{3}{*}{$\begin{array}{l}\text { General } \\
\text { prejudice } \\
\text { factor }\end{array}$} \\
\hline & Specific & Common & Specific & Common & Specific & Common & Specific & Common & \\
\hline & & & & & & & & & \\
\hline Parental prejudice $^{\mathrm{a}}$ & .01 & $.19 * * *$ & $.05^{\mathrm{c}}$ & $.21 * * *$ & $.14 * * *$ & $.12 * * *$ & $.07 * *$ & $.21 * * *$ & $.22 * * *$ \\
\hline Parental RWA & $.08 * *$ & -.01 & -.01 & .01 & -.02 & .02 & -.01 & -.01 & -.02 \\
\hline Parental SDO & -.01 & .01 & .02 & .00 & .03 & .01 & .00 & .01 & -.01 \\
\hline Child RWA & $.16^{* * *}$ & $.27 * * *$ & $.11 * * *$ & $.30 * * *$ & -.03 & $.12 * * *$ & $-.09 * * *$ & $.18 * * *$ & $.24 * * *$ \\
\hline Child SDO & $.08 * * *$ & $.20 * * *$ & .01 & $.21 * * *$ & .02 & $.25 * * *$ & $.14 * * *$ & $.20 * * *$ & $.24 * * *$ \\
\hline \multicolumn{10}{|l|}{ Indirect effects of } \\
\hline \multicolumn{10}{|l|}{ Parental RWA } \\
\hline Via parental prejudice & .00 & $.09 * * *$ & $.01^{\mathrm{c}}$ & $.11 * * *$ & -.00 & $.04 * * *$ & -.00 & $.08 * * *$ & $.12 * * *$ \\
\hline Via child RWA & $.04 * * *$ & $.06 * * *$ & $.03 * * *$ & $.07 * * *$ & -.01 & $.03 * * *$ & $-.02 * * *$ & $.04 * * *$ & $.06^{* * *}$ \\
\hline \multicolumn{10}{|l|}{ Parental SDO } \\
\hline Via parental prejudice & .00 & $.03 * * *$ & -.00 & $.03 * * *$ & $.01 * *$ & $.03 * * *$ & $.01 *$ & $.04 * * *$ & $.04 * * *$ \\
\hline Via child SDO & $.01 * *$ & $.03 * * *$ & .00 & $.03 * * *$ & .00 & $.03 * * *$ & $.02 * * *$ & $.03 * * *$ & $.03 * * *$ \\
\hline \multicolumn{10}{|l|}{ Total effects of } \\
\hline Parental RWA & $.12 * * *$ & $.15^{* * *}$ & .03 & $.19 * * *$ & -.03 & $.09 * * *$ & -.03 & $.11 * * *$ & $.16^{* * *}$ \\
\hline
\end{tabular}




\begin{tabular}{|c|c|c|c|c|c|c|c|c|c|}
\hline Parental SDO & .01 & $.06 * * *$ & .02 & $.06 * * *$ & $.04^{\mathrm{c}}$ & $.07 * *$ & .03 & $.08 * * *$ & $.08 * *$ \\
\hline $\mathrm{R}^{2}$ & .08 & .30 & .02 & .36 & .14 & .35 & .10 & .40 & .42 \\
\hline
\end{tabular}


${ }^{\text {a }}$ Specific/Common component of parental prejudice

Note. Entries are standardized coefficients. All models include control variables.

${ }^{\mathrm{c}} p<.10 ; * p<.05 ; * * p<.01 ; * * * p<.001$ 